$$
\ln \frac{D_{\infty}}{D_{\infty}-D}=\frac{R}{([\mathrm{VA}][\mathrm{HOAc}])}([\mathrm{VA}]+[\text { HOAc }])_{\mathrm{t}}
$$

where $D_{\infty}$ is the equilibrium per cent deuteration and $D$ is the per cent deuteration of the vinyl acetate at time $t$. Since [HOAc] $\gg$ [VA] this reduces to eq 22. $R$ is the rate expression in vinyl

$$
\ln D_{\infty} /\left(D_{\infty}-D\right)=(R /[\mathrm{VA}]) t
$$

acetate, i.e., $R=k$ [VA] for a reaction first order in [VA] or $R=k$ for a reaction zero order in vinyl acetate. From any given run, the order in vinyl acetate cannot be determined since a first-order plot will be obtained no matter what the form of the function $R$. Thus, the order in vinyl acetate can be determined by carrying out kinetic runs at various vinyl acetate concentrations and observing how $R /[\mathrm{VA}]$ varies. If $R=k$ [VA], the vinyl acetate concentrations cancel out and $R=k$. Thus, the rate should not change with [VA].

In the runs containing water some $\mathrm{H}_{2} \mathrm{O}$-catalyzed decomposition of the vinyl acetate was observed. ${ }^{28}$ However, the rate of decomposition was only about $10 \%$ of the rate of exchange. In any case it does not affect the measurement of the rate of exchange as long as the deuterated and nondeuterated vinyl acetates have equal probability of reacting with $\mathrm{H}_{2} \mathrm{O}$.

The runs with propenyl acetates and the cis-butenyl acetate were carried out in the same way except in this case the acetic acid was deuterated initially $\left(20 \% \mathrm{CD}_{3} \mathrm{COOH}\right)$ and each of the starting isomers as well as the isomer being formed were collected for analysis. These runs were made on a 1 - or $2-\mathrm{ml}$ scale because of the smaller amounts of starting materials available. The vpc procedures were the same as those used to collect the samples. The deuterium pick-up of the starting isomer was calculated from the rate expressions for consecutive reactions, ${ }^{37}$

The enol acetate of cyclopentanone was not volatile enough to use the $100 \%$ collection tubes, so $0.4-1.0-\mathrm{ml}$ portions of a 10 or $25-\mathrm{ml}$ reaction mixture were extracted with methylene chloride,

(37) Reference 35, p 166. after which the methylene chloride was washed with water to remove acetic acid. The sample was concentrated and the enol acetate collected by means of preparative vpc using the $20-\mathrm{ft}$ $20 \%$ Carbowax $20 \mathrm{M}$ column at $150^{\circ}$.

The determination of the upper limit for the exchange rate constant was complicated by two factors. First was the Pd(II)catalyzed decomposition ${ }^{1,28}$ of the cyclopentene enol acetate to cyclopentanone and acetic anhydride. For this reason the exchange could only be followed for 2 months, since after this time most of the ester had decomposed. Other reactions occurred as evidenced by the formation of a peak with retention time close to that of the enol acetate. This material was never more than $5 \%$ of the amount of the enol acetate and not enough could be collected for identification. However, it was sufficiently separated from the enol acetate so it did not interfere with the deuterium analysis of the enol acetate. A second complication was the formation of an m/e peak at 129 , which is the same as the parent peak for the trideuterio enol acetate. However, the peak grew quickly, to correspond to about $4 \%$ exchange, but did not continue to grow after that time so it could not be due to exchange of the enol acetate. This initial exchange is believed to result from exchange of an allylic acetate impurity. It was present in too small a quantity to be detected by proton magnetic resonance but it was shown that the allylic ester had the same retention time as the enol ester.

The upper limit for the rate constant was calculated so that after the initial exchange $1 \%$ further exchange could be detected ${ }^{38}$ in the 2 months of the run.

Acknowledgment. The author gratefully acknowledges helpful discussions with Dr. H. G. Tennent and Professors H. Taube, H. Goering, and the late $S$. Winstein; acknowledgment is made for experimental assistance by Mr. R. H. Friant, who carried out the mass spectral work, and Mr. F. Kriss, who did the majority of the laboratory work.

(38) Reproducibility was $\pm 0.3 \%$ on duplicate analyses.

\title{
Tetraphenylethylene. Infrared and Nuclear Magnetic Resonance Evidence on the Nature of the Dianion
}

\author{
Dolan H. Eargle, Jr. \\ Contribution from the Centro de Estudos de Energia Nuclear, \\ Universidade de Coimbra, Coimbra, Portugal. Received September 16, 1970
}

\begin{abstract}
The ir aryl skeletal vibrations $\left(1600-\mathrm{cm}^{-1}\right.$ region) and the $\mathrm{nmr}$ spectrum of tetraphenylethylene dianion $\left(\mathrm{TPE}^{2-}\right)$ have been recorded. Evidence points to the conclusion that the antibonding electrons of the dianion are highly delocalized and that the $\pi$-bonding electrons of TPE ${ }^{2-}$ essentially retain their bonding power, requiring the dianion to assume a nearly planar configuration.
\end{abstract}

$\mathrm{T}$ he consequence of a one-electron reduction of ethylene is the lessening of the $\pi$-bond order by one-half since the "extra" electron is relegated solely to the lowest antibonding orbital. Unrestricted rotation about the $\mathrm{C}_{1}-\mathrm{C}_{2}$ bond is presumably not possible. The effect of a second added electron is to release most of the rotational restraint between the $C_{1}-C_{2}$ bond, since the $\pi$-bond order is then essentially zero.

When this electron pair is highly delocalized, as in tetraphenylethylene dianion ( $\mathrm{TPE}^{2-}$ ), the question of the nature of the resultant molecular species becomes one of considerable interest. This paper is concerned with the application of several spectroscopic investiga- tions toward greater comprehension of the nature of this species.

First, the electron distribution of the anion radical TPE.- should be instructive. A rough calculation of spin density distribution may be made for TPE-- using the data of Cserhegyi, et al., ${ }^{1}$ and adopting the McConnell approximation of $a_{\mathrm{H}}=Q_{\mathrm{C}-\mathrm{H} \rho}{ }^{2}$ Employing ortho, meta, and para hyperfine splitting parameters of $1.52,0.38$, and 2.28 and a $Q$ value of $-24.3 \mathrm{G},{ }^{3}$ the

(1) A. Cserhegyi, J. Jagur-Grodzinski, and M. Szware, J. Amer. Chem. Soc., 91, 1892 (1969).

(2) H. M. McConnell, J. Chem. Phys, 24, 764 (1956).

(3) All three epr splittings have been given positive signs, in keeping with observations that upfield $\mathrm{nmr}$ shifts of anion radicals correspond to 


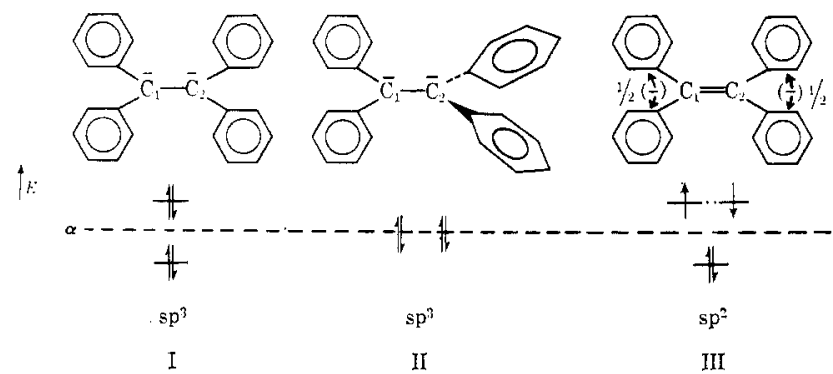

Figure 1. Highest occupied energy orbitals of TPE2- in a planar configuration (I), a "twisted" configuration (II), and a planar-delocalized electron ccnfiguration (III). Pairing of the odd electrons is required in III.

total spin density is to be found only at the ortho, meta, and para positions. ${ }^{4}$ Thus, barring improbable negative spin on both the $\mathrm{C}_{1}$ and $\mathrm{C}_{2}$ of the ethylenic portion of the radical, there is almost complete delocalization of the odd electron. In this case, then, the $C_{1}-C_{2} \pi$ bonding should be left pretty much intact and a planar anion should result.

Molecular orbital theory indicates that the second added electron should be found in an orbital essentially the same (except for spin) as that of the first electron. If the first is highly delocalized, then the second should be also. The dianion TPE ${ }^{2-}$ is of ten represented by the valence-bond structure I (Figure 1). ${ }^{5}$ It seems logical to expect that Coulombic repulsion of adjacent electron pairs in this structure does not favor its stability, especially in light of the above-demonstrated odd-electron delocalization into the four adjacent benzene rings of TPE.-. Relatively "tight" ion pairing between the carbanions on $C_{1}$ and $C_{2}$ and the gegenion has been invoked to "stabilize" this structure.,5b Also geometrical "twists" have been used to help stabilize II by diminishing the Coulombic repulsion of adjacent electron pairs. If, however, these "extra" electrons do delocalize to a large extent, we reason that the $C_{1}-C_{2} \pi$ bonding electrons should continue to prevail and that free rotation about the $C_{1}-C_{2}$ bond would remain severely restricted (structure III). This latter explanation assumes, of course, that there is little or no rehybridization of the $C_{1}$ and $C_{2}$ bonding into structures resembling II (Figure 1).

The energy of the disproportionation reaction (eq 3 ) and conformation requirements for the triplet state in the similar molecule stilbene favor the choice of II for TPE ${ }^{2-5,6}$ but, as pointed out above, this conformation should be the most favored only upon localization of the extra electrons on $C_{1}$ and $C_{2}$. If TPE ${ }^{2-}$ assumes the geometry of III we must show that there is considerable electron density upon the benzene rings. ${ }^{7}$

positive spin densities (see Table II): M. E. Anderson, P. J. Zandstra, and T. R. Tuttle, J. Chem. Phys., 33, 1591 (1960).

(4) A similar conclusion was drawn in the case of TPR + by I. C. Lewis and L. S. Singer, ibid., 43, 2725 (1965).

(5) (a) J. F. Garst, J. G. Pacifici, and E. R. Zablotny, J. Amer. Chem. Soc., 88, 3872 (1966), and earlier papers listed therein; (b) R. C. Roberts and M. Szwarc, ibid,, 87, 5542 (1965).

(6) A. S. Hammond, J. Saltiel, A. A. Lamola, N. J. Turro, J. S. Bradshaw, D. O. Cowan, R. O. Counsell, V. Vogt, and C. Dalton, ibid., 86, 3197 (1964).

(7) This argument parallels that of Adam and Weissman for triphenylmethyl in that "twisting" causes less, not more spin density upon the aryl rings: F. C. Adam and S. I. Weissman, ibid., 80, 2057 (1958).

\section{Experimental Section}

Infrared measurements were performed on Perkin-Elmer 21, 221, and 521 and Beckman IR-10 double-beam instruments using solvent reference cells. Reductions were carried out in vacuo by alkali metal in dimethyoxyethane or diethyl ether solvent. ${ }^{8}$ Samples were approximately $40 \mathrm{mg}$ in quantity in $4-5 \mathrm{ml}$ of solvent and were prepared in "cavity cells" glued to Pyrex tubing. Other solvents such as tetrahydrofuran and dioxane are not as useful for this type of ir investigation since they possess absorptions in the regions under investigation. Best results were obtained with slits open near $100 \mu$ and increased source intensity.

The epr spectra were obtained on a Varian V-4502 spectrometer and the nmr spectra on a Varian HA-100 instrument, both of this laboratory.

Nmr Experiments. During the course of these investigations, an attempt was made to determine via $\mathrm{nmr}$ if the dianion was actually fixed in a twisted position or if rotation occurred. The dianion is presumably diamagnetic and would give two sets of aromatic peaks if opposite ends of the molecule were in inequivalent orientations, i.e., "twisted" fixed or slowly rotating. The results were somewhat complex and are compiled in Table I. The

Table I. Nmr Observations of TPE and TPE ${ }^{2-}$

\begin{tabular}{|c|c|c|c|}
\hline $\begin{array}{l}\text { Molecular } \\
\text { species }\end{array}$ & Solvent & Cation & Results \\
\hline TPE & Diethyl ether & & Single sharp peak, $\delta 7.01$ \\
\hline TPE $^{2-}$ & Diethyl ether & $\mathrm{Na}^{+}$ & $\begin{array}{l}\text { Broad asym peak, } \delta 7.04 \\
(3.0 \text { cps upfield of TPE) }\end{array}$ \\
\hline $\mathrm{TPE}^{2-}$ & Diethyl ether & $\mathrm{K}^{+}$ & $\begin{array}{l}\text { Highly unstable solution, } \\
\text { less intense color than } \\
\mathrm{Na}^{+}\end{array}$ \\
\hline TPE & THF & & Single sharp peak, $\delta 7.16$ \\
\hline $\mathrm{TPE}^{2-}$ & $\begin{array}{l}\text { THF or } \\
\text { DME }\end{array}$ & $\mathrm{K}^{+}$ & $\begin{array}{l}\text { Three broad low peaks, } \\
\delta 5.68,6.57,7.07 ; \\
\text { ratios } 2: 2: 1 ; \text { some } \\
\text { splitting evident; no } \\
\text { peak at } \delta 7.16 \text { (TPE) }\end{array}$ \\
\hline
\end{tabular}

diethyl ether solution of $\mathrm{TPE}^{2-}, 2 \mathrm{Na}^{+}$has been reported as being almost entirely dianion; ${ }^{9}$ however, there is only a small difference in the nmr absorptions of the neutral and the dianion species. On the other hand, the THF or DME solutions of TPE ${ }^{2-}, 2 \mathrm{~K}^{+}$exhibit a species entirely different from that of TPE (neutral). Three broad peaks with ratios 2:2:1 and large ortho, meta, and para shifts were observed. The spectrum was complicated, nevertheless, by the presence of the paramagnetic anion radical TPE.-. We obtained an epr spectrum of this solution (in the nmr sample tube) fully as well resolved as the published epr spectrum of metal-free TPE. ${ }^{-1}$ The presence of TPE.- no doubt caused the considerable broadening of the nmr lines. It is evident that the nmr differences in the TPE ${ }^{2-}, 2 \mathrm{Na}^{+}-$diethyl ether and the $\mathrm{TPE}^{2-}, 2 \mathrm{~K}^{+}-$ THF or -DME species are due largely to solvation differences.

From these nmr data, therefore, we must conclude that, under the experimental limitations, the free $T P E^{2-}$ is either fixed in a planar configuration or rapidly rotating, either situation resulting in magnetically equivalent aryl groups.

It has been assumed" that "saturation" by metal of the THF solution of TPE would result in a complete conversion of TPE to TPE ${ }^{2-}$ (eq 1 and 2) and, if followed by addition of TPE, could

$$
\begin{gathered}
\mathrm{TPE}+\mathrm{M}=\mathrm{TPE} \cdot{ }^{+}, \mathrm{M}^{+} \\
\mathrm{TPE} \cdot{ }^{-}, \mathrm{M}^{+}+\mathrm{M}=\mathrm{TPE}^{2-}, 2 \mathrm{M}^{+} \\
\text {2(TPE.- }, \mathrm{M}^{+}=\mathrm{TPE}^{2-}, 2 \mathrm{M}^{+}+\mathrm{TPE}
\end{gathered}
$$

give equilibrium constants for the disproportionation reaction (eq 3). Our attempts to obtain paramagnetic free TPE ${ }^{2-}$ by saturating TPE with K in THF show this procedure to be ineffective, since apparently eq 2 does not lie completely to the right, even in the presence of an excess of metal.

A further experiment proved this indeed to be the case. A

(8) D. H. Eargle, Jr., and E. W. Cox, "The Alkali Metals," Special Publication No. 22, The Chemical Society, London, 1967, pp 116-124; D. H. Eargle, Jr., J. Org. Chem., 35, 3744 (1970); J. Chem. Soc. B, $1556(1970)$.

(9) J. F. Garst and R. F. Cole, J. Amer. Chem. Soc., 84, 4352 (1962). 
Table II. Infrared Frequencies

\begin{tabular}{|c|c|c|c|c|}
\hline Molecular species & $\mathrm{C}=\mathrm{C}$ stretch, $\mathrm{cm}^{-1}$ & Ar $1600-\mathrm{cm}^{-1}$ region & $\Delta \nu$ & Ref \\
\hline Styrene & 1640 & 1605,1585 & & $a$ \\
\hline cis-Stilbene & 1605 & 1578 & & $b$ \\
\hline trans-Stilbene & Inactive & 1600 & & $b$ \\
\hline Biphenyl & & 1600 & 32 & $c$ \\
\hline Biphenyl - & & 1568 & 32 & $c$ \\
\hline Naphthalene & & 1600 & 33 (av) & $c$ \\
\hline Naphthalene - & & 1587,1521 & & \\
\hline Benzophenone & & 1598 & 18 & $c$ \\
\hline Benzophenone - & & 1580 & & \\
\hline $\begin{array}{l}\text { Tetraphenylethylene } \\
\text { TPE }{ }^{2-}\end{array}$ & $\begin{array}{l}\text { Inactive } \\
\text { Not observable }\end{array}$ & $\begin{array}{l}1600\left(\mathrm{CCl}_{4}\right) \\
1556 \pm 5\left(\mathrm{~K}^{+}, \mathrm{DME}\right) \\
1553 \pm 5\left(\mathrm{Na}^{+}, \mathrm{Et}_{2} \mathrm{O}\right)\end{array}$ & 36 & $d$ \\
\hline Tetracyanoethylene & $\begin{array}{l}\text { Inactive } \\
\quad(1568 \text { Raman })^{e}\end{array}$ & & & \\
\hline TCNE.- & $1500^{f}$ & & & $d$ \\
\hline $\begin{array}{l}\text { Triphenylmethyl } \\
\text { chloride }\end{array}$ & & 1600 & 41 & $d$ \\
\hline Triphenylmethyl- & & 1559 & & \\
\hline
\end{tabular}

${ }^{a}$ Reference 10, p $368 .{ }^{b}$ D. S. Brackman and P. H. Plesch, J. Chem. Soc., 2188 (1952). ${ }^{c}$ Reference 8. ${ }^{d}$ This work. Triphenylmethyl radical contains ca. 0.6 electron on the methyl carbon (see ref 8.) • D. A. Long and W. O. George, Spectrochim. Acta, 19, 1728 (1963). i Note: $C=N$ (conjugated) is always 1560 , and $C=N$ would be an extreme condition and would have to be shared by three others.

solution of $\mathrm{TPE}^{2-}, 2 \mathrm{Na}^{+}$was prepared in diethyl ether by allowing TPE to stand over the metal for several days in order to assure complete conversion to the dianion. At the end of this time no epr signal could be detected even under high modulation conditions. At this time, the diethyl ether solvent was removed and replaced by THF. The reappearance of the TPE.-, $\mathrm{Na}^{+}$epr signal, distorted as usual by the presence of dianion I, showed then that eq 2 lies essentially to the right in diethyl ether, and that in THF there is some solvent competition for one metal ion, forcing the equilibrium partially to the left. ${ }^{8}$ The extent of line broadening of the three nmr peaks could be caused by $1-5 \%$ TPE.--, as a rough estimate. It may be possible, however, to determine the position of equilibrium of eq 2 in various solvents by a comparison of the intensities of the epr signals with those of $\mathrm{nmr}$ signals.

An attempt to prepare $\mathrm{TPE}^{2-}, 2 \mathrm{~K}^{+}$in diethyl ether was unsuccessful. The red solution, which was of a slightly different color than the corresponding $\mathrm{Na}^{+}$solution, decomposed within minutes to a brown material.

\section{Results and Discussion}

Recently developed methods of infrared analysis of anion radicals ${ }^{8}$ allow observation of $\mathrm{TPE}^{2-}$ and comparison with other aryl radicals (Table II). Two regions of the spectrum are to be considered, the 1600$\mathrm{cm}^{-1} \mathrm{C}=\mathrm{C}$ stretching frequency and the aromatic "quadrant stretching" occurring in the region 1640$1600 \mathrm{~cm}^{-1} \cdot{ }^{10}$ Several aryl ethylenes are shown in Table II to typify the stretching frequencies of arylconjugated double bonds. Among these, trans-stilbene and tetraphenylethylene have no observed $\mathrm{C}=\mathrm{C}$ stretching in the infrared owing to symmetry taboos (likewise, tetracyanoethylene (TCNE), though it is not aryl). ${ }^{11}$ One set of characteristic frequencies of aryl skeletal vibrations of unreduced species appears near $1600 \mathrm{~cm}^{-1}$. Upon reduction to the anion radical or ketyl this frequency range of all these compounds is lowered, ${ }^{8}$ as expected, since additional electron density in the aryl ring would be expected to "loosen" the

(10) N. B. Colthup, L. H. Daly, and S. E. Wiberly, "Introduction to Infrared and Raman Spectroscopy," Academic Press, New York, N. Y., 1964, pp 220-224. Colthup envisions the two components of the $1600-\mathrm{cm}^{-1}$ skeletal vibration region of benzene rings as "opposite quadrants of the ring stretching while the intervening quadrants contract," This view is indeed a simplification of true conditions, but does lend a certain convenience of description to skeletal vibrations.

(11) Some models ${ }^{12}$ show twisting, but TPE in Nujol, $\mathrm{KBr}$, diethyl ether, and dimethoxyethane shows no $1600-1700-\mathrm{cm}^{-1} \mathrm{C}=\mathrm{C}$ stretching absorption whatsoever.

(12) G. Favini and M. Simonetta, Theor. Chim. Acta, 1, 294 (1963). bonds of the aryl rings by some amount. The important observation to be made here is that, allowing for some variation due to molecular type and substitution, all aryl "quadrant stretching" frequencies appear near $1560-1580 \mathrm{~cm}^{-1}$ in the anion radicals. This includes TPE ${ }^{2-}$. Thus, TPE ${ }^{2-}$ appears to be much more like benzophenone ketyl or biphenyl anion radical than like the unreduced form.

Lest the question be raised that what we are seeing at $1560 \mathrm{~cm}^{-1}$ is a slightly twisted (hence, no longer forbidden by symmetry selection rules) and somewhat loosened $\mathrm{C}=\mathrm{C}$, the ir results from TCNE.- are given in Table II. The $\mathrm{C}=\mathrm{C}$ portion of TCNE - contains about 0.6 of the odd electron. ${ }^{13}$ This 0.6 electron loosens the $\mathrm{C}=\mathrm{C}$ stretching from $1568 \mathrm{~cm}^{-1}$ (Raman) to $1500 \mathrm{~cm}^{-1}$; a two-electron reduction to $\mathrm{TCNE}^{2-}$ would certainly yield much lower frequencies. Comparable results would be expected in a TPE ${ }^{2-}$ in which the two electrons were only partly delocalized.

The aryl rings of benzophenone - contain about 0.6 electron ( 0.3 per ring); ${ }^{14}$ those of biphenyl.- contain 0.5 electron per ring. Since the observed ir frequency of TPE $2-$ is close to that of biphenyl.- and other anion radicals, ${ }^{8}$ it is probable that delocalization of each odd electron in TPE ${ }^{2-}$ is considerable.

It is obvious that this argument has so far avoided the problem of actually localizing the cation, either tightly or loosely near $C_{1}$ or $C_{2}$, and it does not seem necessary to do this. Conductance measurements ${ }^{5 b}$ and other evidence for the nature of the solvated anion and triple ions involved would remain valid, even though the antibonding electrons were found to be more highly delocalized than originally supposed. These observations, however, do no injury to the thermochemical calculations involving the disproportionation reaction of TPE - - (eq 3).

On the basis of the large $\left(36 \mathrm{~cm}^{-1}\right)$ shift in the quadrant stretching frequency of $\mathrm{TPE}^{2-}$, the distribution of the electron density of the TPE.- anion, and the nmr evidence of equality of the magnetic environment of the

(13) J. Gendell, J. H. Freed, and G. K. Fraenkel, J. Chem. Phys., 41, 949 (1964).

(14) P. H. Rieger and G. K. Fraenkel, ibid., 37, 2811 (1962). 
four aryl rings of $\mathrm{TPE}^{2-}$, we are drawn to the conclusion that $\mathrm{TPE}^{2-}$ must actually exist in a nearly planar state (III) with the antibonding electrons highly delocalized. It is therefore unlikely that rehybridization at $C_{1}$ and $C_{2}$ of the ethylenic portion (structures I or II) occurs to any great extent, since the $\pi$-bonding electrons are only slightly countered.

Acknowledgments. Thanks are in order for provocative discussions with Professor Edward Janzen of the University of Georgia and Dr. Yecheskel Rasiel of the Cooper Union. Mr. Ronald Emrich performed many of the early ir experiments and Mr. Carlos Geraldes performed many of the epr experiments, and thanks are due them, as they are to Dr. R. J. Suffolk of the University of Southampton, England, for running the nmr experiments. My appreciation also goes to the Instituto de Alta Cultura (Portugal) for a research grant.

\title{
Effect of Pressure on the Ligand-Field Spectra of Some Five-Coordinate Nickel(II) Complexes ${ }^{1}$
}

\author{
J. R. Ferraro,* D. W. Meek, ${ }^{*}$ E. C. Siwiec, and A. Quattrochi \\ Contribution from the Chemistry Division, Argonne National Laboratory, \\ Argonne, Illinois 60439. Received October 21, 1970
}

\begin{abstract}
The pressure effects on the ligand-field spectra of several five-coordinate Ni(II) complexes are reported. The spectra of trigonal-bipyramidal structures are extremely pressure sensitive and shift to higher energies; those of square-pyramidal structures are less sensitive to pressure. The method may be used to distinguish between a trigonal-bipyramidal and a square-pyramidal structure in lieu of, or in complementation with, X-ray crystallography.
\end{abstract}

$\mathrm{I}^{\mathrm{n}}$ recent years many complexes of five-coordinate transition metals involving mono-, bi-, tri-, and tetradentate ligands have been reported. Several reviews on the subject have been written. ${ }^{2-5}$ Of particular interest to the discussion of this paper are the complexes involving tetradentate "tripod-like" ligands. ${ }^{6-19}$ Characterization and, in some cases, X-ray structural determinations have been made on complexes of the type [MLX]Y, where $\mathrm{L}$ is a tetradentate ligand, $\mathrm{X}$ is a halide or pseudohalide, $Y$ is usually a large polyatomic anion, and $\mathrm{M}=\mathrm{Ni}(\mathrm{II}), \mathrm{Co}(\mathrm{II}), \mathrm{Pd}(\mathrm{II})$, or $\mathrm{Pt}(\mathrm{II}) .{ }^{6-25}$

(1) Based on work performed under the auspices of the U, S. Atomic Energy Commission.

(2) L. M. Venanzi, Ric. Sci., 34 (7), 3 (1964).

(3) M. J. Norgett, J. H. M. Thornley, and L. M. Venanzi, Coord. Chem. Rev., 2, 99 (1967).

(4) M. Ciampolini, Struct. Bonding (Berlin), 6, 52 (1969).

(5) L. Sacconi, Pure Appl. Chem., 17, 95 (1968).

(6) G. S. Benner, W. E. Hatfield, and D. W. Meek, Inorg. Chem., 3, 1544 (1964).

(7) G. Dyer and D. W. Meek, ibid., 4, 1398 (1965).

(8) G. Dyer and D. W. Meek, ibid., 6, 149 (1967).

(9) M. O. Workman, G. Dyer, and D. W. Meek, ibid, 6, 1543 (1967).

(10) G. S. Benner and D. W. Meek, ibid., 6, 1399 (1967)

(11) C. A. McAuliffe and D. W. Meek, ibid., 8, 904 (1969).

(12) J. A. Brewster, C. A. Savage, and L. M. Venanzi, J. Chem. Soc., 3699 (1961)

(13) C. A. Savage and L. M. Venanzi, ibid., 1548 (1962).

(14) G. Dyer and L. M. Venanzi, ibid., 2771 (1965).

(15) L. Sacconi and R. Morassi, ibid., A, 2904 (1969)

(16) L. Sacconi and R. Morassi, ibid., A, 2997 (1968); 575 (1970).

(17) L. Sacconi and I. Bertini, J, Amer. Chem. Soc., 89, 2235 (1967)

90,5443 (1968).

(18) L. Sacconi, I, Bertini, and F. Mani, Inorg. Chem., 7, 1417 (1968)

(19) L. P. Haugen and R. Eisenberg, ibid, 8, 1072 (1969).

(20) G. A. Mair, H. M. Powell, and L. M. Venanzi, Proc. Chem Soc., London, 170 (1961).

(21) D. L. Stevenson and L. F, Dahl, J, Amer. Chem. Soc., 89, 3424 (1967).

(22) C. M. Harris, R. J. Nyholm, and D. J. Phillips, J. Chem. Soc., $4379(1960)$.

(23) G. A. Barclay and R. J. Nyholm, Chem. Ind. (London), 378 (1953),
The $X$-ray structural studies have shown that the fivecoordinate $\mathrm{MLX}^{+}$ions may approximate either a trigonal-bipyramidal or a square-pyramidal structure.

Most of the ligand-field spectra measured for these complexes have been limited to ambient temperatures. These materials had never been studied under pressure, and it was of interest to examine the effects of pressure on their ligand-field spectra. Pressure effects on the electronic spectra of several transition metal complexes have been previously studied by Drickamer and coworkers $^{26}$ and others. ${ }^{27,28}$ While this work was in progress, Gray, Venanzi, and coworkers ${ }^{29}$ measured the electronic spectra of some of these complexes at $77^{\circ} \mathrm{K}$. This paper reports the effects of high pressure on the ligand-field spectra of five-coordinate $\mathrm{Ni}(\mathrm{II})$ complexes where the ligand may be mono-, bi-, tri-, and tetradentate. For comparison, Ni(II) complexes of other coordination numbers were also studied, as well as several $\mathrm{Co}(\mathrm{II})$, two $\mathrm{Pd}(\mathrm{II})$, and one $\mathrm{Pt}(\mathrm{II})$ five-coordinate complexes.

\section{Experimental Section}

The metal complexes studied in this paper have been prepared, analyzed, and reported elsewhere. ${ }^{7-11,16,17}$ Table I lists the sym-

(24) G. A. Mair, H. M. Powell, and D. E. Henn, Proc. Chem. Soc., London, 415 (1960).

(25) D. W. Meek and J. A. Ibers, Inorg. Chem., 8, 1915 (1969).

(26) H. G. Drickamer, Solid State Phys, 17, 1 (1965), and references therein.

(27) H. W. Offen and D. E. Hein, J. Chem. Phys., 50, 5274 (1969). B. A. Baldwin and H. W. Offen, ibid., 49, 2933, 2937 (1968); 48, 5358 (1968); H. W. Offen and D. T. Phillips, ibid., 49, 3995 (1968); A. H. Kahin and H. W. Offen, ibid., 48, 749 (1968); H. W. Offen and R. A. Beardslee, ibid., 48, 3584 (1968); T. T. Nakashima and H. W. Offen, ibid., 48, 4817 (1968).

(28) L. S. Whatiey, Advan. High Pressure Res., 1, 327 (1966), and references therein.

(29) J. W. Dawson, L. M. Venanzi, J. R. Preer, J. E. Hix, and H. B. Gray, J. Amer. Chem. Soc., 93, 778 (1971). 